\title{
EVOLUTIONARY CORRELATIONS OF POLYCYCLIC SHOOT GROWTH In ACER (SAPINDACEAE) ${ }^{1}$
}

\author{
Miguel Verdú ${ }^{2,4}$ AND José Climent ${ }^{3}$ \\ ${ }^{2}$ Centro de Investigaciones sobre Desertificación (CSIC-UV-GV), Apartado Oficial, 46470 Albal (Valencia), Spain; and \\ ${ }^{3}$ CIFOR, Instituto Nacional de Investigaciones Agrarias y Alimentarias (INIA), Apdo 8111, 28080 Madrid, Spain
}

\begin{abstract}
Two strategies have evolved in understory trees in relation to light availability: maximization of light capture and shade tolerance. In the genus Acer, light capture is favored by a suite of traits maximizing twig thickness and leaf size and minimizing the density of branching in the crown. In contrast, shade tolerance is enhanced by minimizing crown area, crown volume, and total leaf area per unit height. Maples with polycyclic shoot growth (i.e., successive flushes of shoot growth separated by a resting phase within the same vegetative period) may benefit from the prolonged growth by growing more and increasing total leaf area; thus we hypothesize that polycyclism is evolutionarily correlated with the suite of traits related to light capture. We tested this hypothesis using different phylogenetic trees to explore correlations between polycyclism and both suites of traits. Polycyclism was correlated with the suite of traits maximizing light capture, suggesting that polycyclic maples are "optimists" (i.e., they make vigorous vertical extensions in rich light) and monocyclic maples are "pessimists" (i.e., they wait in the dark understory until a gap is opened). Both strategies have been described for different floras, and interestingly, polycyclic species recruit over a wider range of environments than the monocyclic species.
\end{abstract}

Key words: comparative method; heterochrony; light competition; shade tolerance; understory maples.

Light is a crucial resource for survival and growth of understory plants and consequently, the mechanisms underlying interspecific variation in growth of tree seedlings in contrasting light conditions have been examined in many studies (Canham et al., 1999 and references therein).

The genus Acer (maples) includes species with different growth strategies in relation to light availability: some species maximize light capture and others tolerate shade (Lei and Lechowicz 1990, 1997a, b, 1998; Sipe and Bazzaz, 1994, 1995). Ackerly and Donoghue (1998) have shown that two independent suites of coevolving traits may explain the plant canopy structure in understory maples. The first suite of traits follows Corner's (1949) rules, who suggested that twig thickness; leaf, inflorescence, and seed sizes; and tree height are positively correlated in the morphological evolution of trees and negatively correlated to the density of branching in the crown. This suite of traits seems to be associated with the maximization of light capture in the understory. The second suite of characters is related to sapling crown allometry, including crown size, stem diameter, and total leaf area, and seems to be associated with shade tolerance.

Indeed, a strong correlation among the vegetative and reproductive traits described is expected because of biomechanical and/or resource supply requirements that have led to correlational selection in Acer (Verdú and Gleiser, 2006). For example, we would expect a positive correlation between twig and leaf sizes if larger leaves need longer twigs for

\footnotetext{
${ }^{1}$ Manuscript received 15 December 2006; revision accepted 8 June 2007.

The authors thank D. Ackerly for providing the DNA data matrix and for his advice on the comparative method; M. Kozlov, P. C. de Jong and P. GarcíaFayos for their comments on the manuscript; J. G. Pausas, who kindly wrote a macro that allowed the application of the phylogenetic correlations to the MCMC sampled trees; and R. Chambel for English editing of the final version. This paper was funded by the Spanish Ministerio de Educación y Ciencia (project AGL2005-07440-C02-02/FOR). J. Climent was granted a Ramón y Cajal fellowship of the Spanish Ministry for Education and Science.

${ }^{4}$ Author for correspondence (e-mail: Miguel.Verdu@uv.es), phone: +34-961220540, fax: +34-961270967
}

biomechanical support (Verdú and Gleiser, 2006). In early studies on shoot growth in the genus Acer, heterochrony was postulated to be the ontogenetic mechanism underlying the development of annual shoots in adult plants because polycyclic shoots in adult maples usually have juvenile leaves (Critchfield, 1971; Steingraeber, 1982).

Polycyclic shoot growth (i.e., successive shoot flushes separated by a resting phase within the same vegetative period) can occur either as the consequence of extreme environmental conditions in many species or as a species-specific developmental strategy under normal conditions. Polycyclism in Acer is a species-specific strategy distinguished by de Jong (1976, p. 168 ), who noted, "When during the summer shoot growth continues, only a part of the taxa, and mainly those with few bud scales, show continuous development of normal leaves. In the remaining taxa elongation stops, at least temporarily, after the expansion of the embryonic shoot in the winter bud and prolonged extensions growth is, or tends to be, discontinuous through the formation of disguised lamnas [sic] shoots." Thus, annual shoot growth of Acer species may be classified as monocyclic or polycyclic. Polycyclic shoot growth is a developmental phenomenon that has been associated with the search for better light conditions (Kaya et al., 1994). Linking predictions by Ackerly and Donoghue (1998) to the ontogenetic mechanism of shoot growth, we hypothesize that polycyclism is evolutionarily correlated with the first constellation of characters associated with light competition. More specifically, we hypothesize that maples with polycyclic shoots may benefit from the prolonged growth by growing more and increasing total leaf area. Differences in tree size would also be expected under each of the two shoot growth strategies because polycyclic species will tend to maximize the aboveground growth at the expense of allocation to carbohydrate reserves (Canham et al., 1999). If this is true, we would expect polycyclism to be positively correlated with leaf size, twig thickness, inflorescence size, seed size, and tree height and negatively correlated with the density of crown branching. In contrast, if polycyclism is associated with the second suite of 


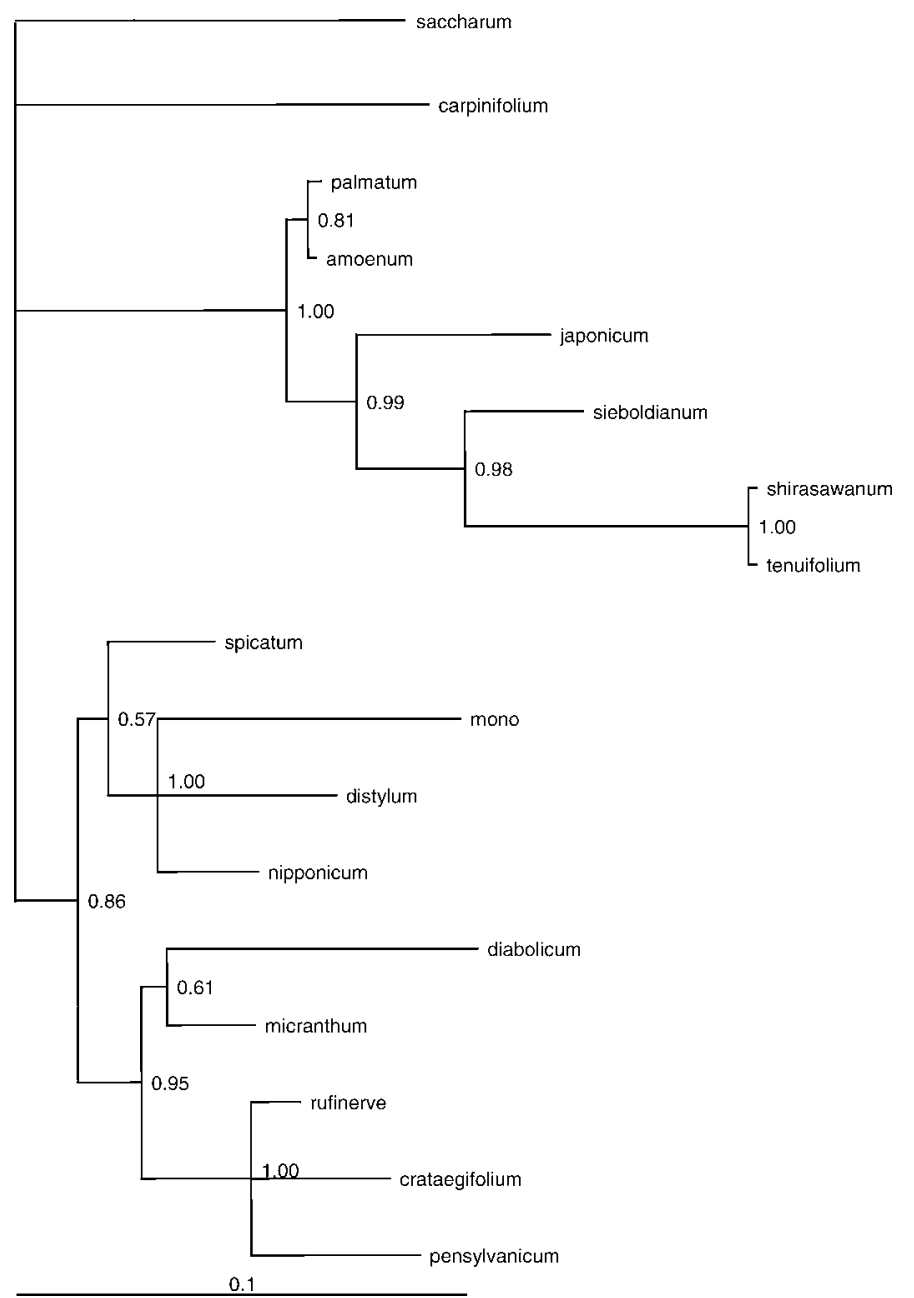

Fig. 1. The 50\% majority-rule consensus tree of Acer species based on a Bayesian analysis of ITS sequence data. The interior node labels are the posterior probabilities of the clades (i.e., the number of times a particular node appeared in the Markov chain Monte Carlo MCMC sample). The branch lengths are measured in expected substitutions per site.

characters (those allowing shade tolerance), we would expect polycyclism to be negatively correlated with crown size, stem diameter, and total leaf area. We tested both scenarios by using different phylogenetic trees to determine whether polycyclism was correlated with both suites of traits. This information is relevant both for increasing our knowledge of the phenotypic evolution of the genus Acer and for determining how shoot phenology can combine in different ways with sapling allometry and growth. The latter is most relevant for ecophysiological and silvicultural research on understory maples under different climatic scenarios.

\section{MATERIALS AND METHODS}

To test the evolutionary correlations of shoot growth polycyclism in Acer, we used the traits that better explain (i.e., those with higher loading factors) the two suites of characters in the principal component analysis of Ackerly and Donoghue (1998). These traits were twig thickness (TCSA), shoot leaf area (ShLA), leaf size (LfPt), number of growing tips per unit crown area (CATP-P),

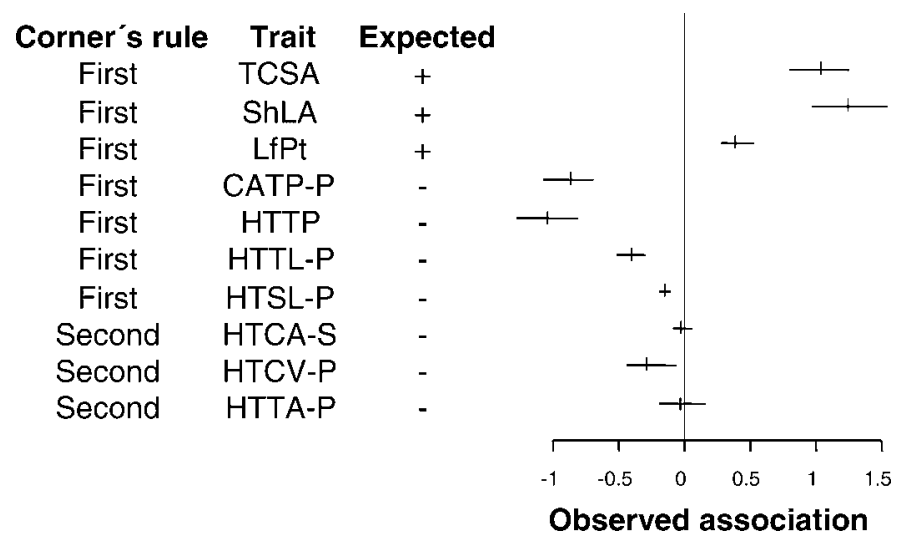

Fig. 2. Evolutionary correlations between polycyclism (coded as mono- and polycyclism) and the traits involved in the first and the second constellations of characters defined by Ackerly and Donoghue (1998). For the first Corner's rule, such traits are twig thickness (TCSA), shoot leaf area (ShLA), leaf size (LfPt), number of growing tips per unit crown area (CATP-P), number of growing tips per unit height (HTTP-P), total shoot length per unit height (HTTL-P), and main stem length per unit height (HTSL-P). For the second Corner's rule, the main traits were those indicating covariation in crown area, crown volume, and total leaf area in saplings of equivalent height (HTCA-S, HTCV-P, and HTTA-P, respectively). The Corner's rules define two different ecological scenarios in which polycyclism is associated with characters maximizing light capture (First rule) or allowing shade tolerance (Second rule). The sign of the expected association under each scenario is provided in the third column. The mean and the interval of estimations of the observed association in the 3000 phylogenetic trees are given in the second row.

number of growing tips per unit height (HTTP-P), total shoot length per unit height (HTTL-P), and main stem length per unit height (HTSL-P) for the first principal component. For the second principal component, the main traits were those indicating covariation in crown area, crown volume, and total leaf area in saplings of equivalent height (HTCA-S, HTCV-P, and HTTA-P, respectively).

Like Ackerly and Donoghue (1998), we restricted the analysis to understory maples to reflect interspecific evolutionary differentiation rather than environmentally dependent variation analysis (see Fig. 1 for the identity of the 17 Acer species). All the maple species found in the study sites (temperate deciduous forests of eastern North America and Japan) were sampled, thus minimizing the bias in species selection with respect to the ecological hypothesis tested here. For a full description of sampling sites, procedures, data and descriptive statistics of the species, see Ackerly and Donoghue (1998).

The number of bud scales was used as a surrogate of shoot-growth polycyclism. The number of bud scales is a taxonomic character in the genus Acer that is also associated with the shoot type because species with continuous (monocyclic) growth have few bud scales, whereas species with discontinuous (polycyclic) growth have numerous bud scales according to de Jong (1976). De Jong gave information on the number of bud scales for each taxonomic series, and split the genus into two different groups based on the clear-cut point of four pairs of bud scales. Thus, we assigned all the species with less than four bud scale pairs to the monocyclic group and those with more than four bud scale pairs to the polycyclic group.

Under the scenario of shoot-growth polycyclism being associated with characters maximizing light capture (first suite of traits), we would expect positive correlations between polycyclism and TCSA, ShLA, and LfPt and negative correlations with CATP-P, HTTP-P, HTTL-P, and HTSL-P. In contrast, under the scenario in which polycyclism is associated with traits allowing shade tolerance (second suite of characters), we would expect polycyclism to be positively correlated with HTCA-S, HTCV-P, and HTTA-P. All the traits considered were taken from Ackerly and Donoghue (1998); values were log-transformed for the analyses.

The phylogenetic association of shoot-growth polycyclism with such characters was tested by means of a generalized estimating equation (GEE) procedure that uses a generalized linear model (GLM) approach incorporating 

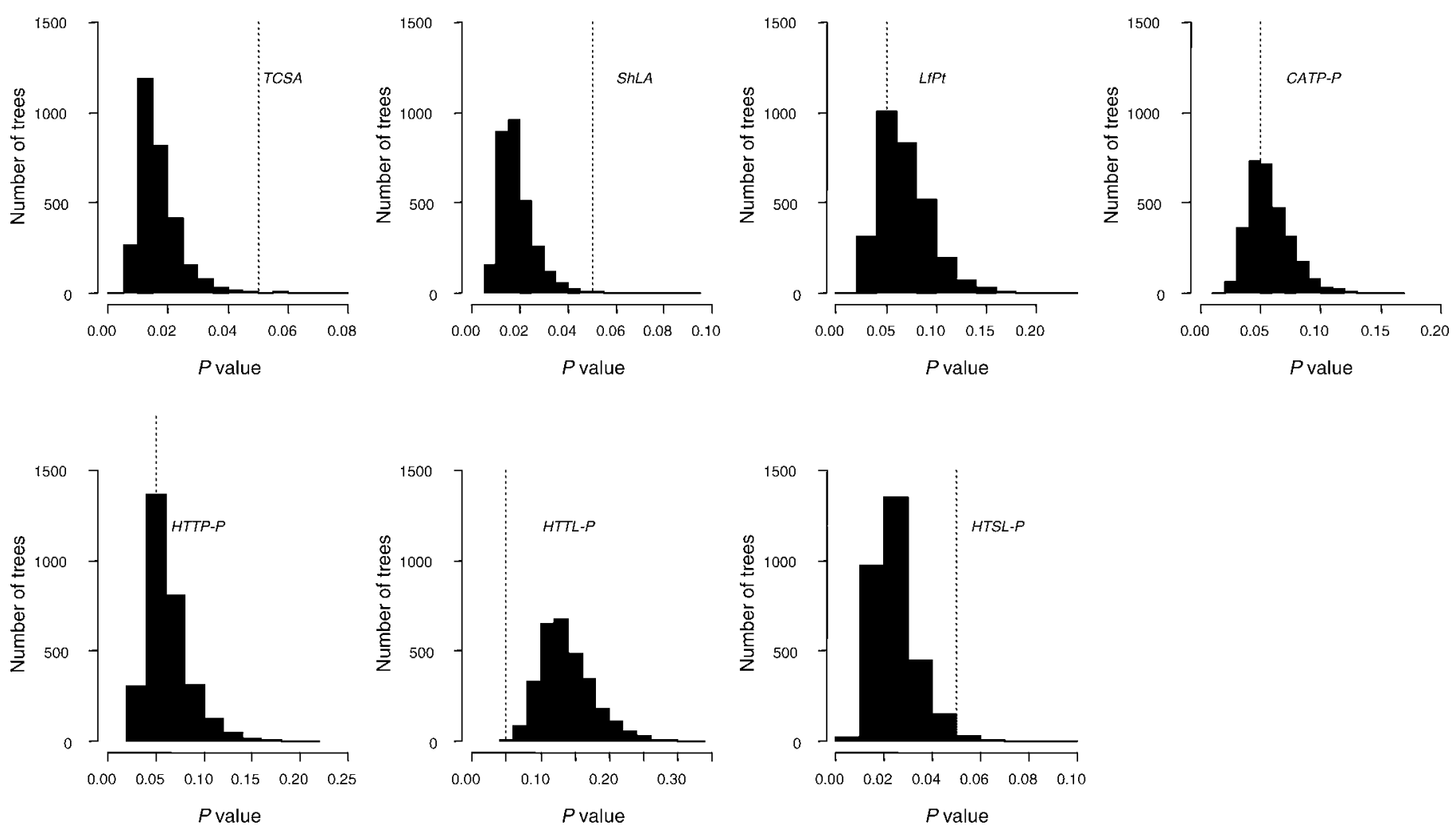

Fig. 3. The frequency distribution of the $P$ values obtained in the 3000 phylogenetic trees that were used to test the evolutionary correlation between polycyclism and the traits involved in the first suite of characters (those maximizing light capture) defined by Ackerly and Donoghue (1998). Dotted line indicates $P=0.05$. See Fig. 2 for trait abbreviations.

the phylogenetic relatedness among species as a correlation matrix in the model. GEE analyses were done with the "compar.gee" function within the APE software package (Paradis and Claude, 2002).

To account for the uncertainty in the topology of the phylogenetic trees and their branch lengths, we ran the GEE model for 3000 different phylogenetic trees. Those trees were obtained in a Bayesian analysis performed in the program MrBayes 3.1.2 (Huelsenbeck and Ronquist, 2001), which uses the Markov chain Monte Carlo (MCMC) procedure to sample trees reconstructed from the nuclear ribosomal ITS sequences of the 17 understory Acer species studied by Ackerly and Donoghue (1998). The best-fit model of DNA substitution selected by the hierarchical likelihood ratio test, as implemented in the HYPHY software (Posada and Crandall, 1998; Kosakovsky Pond et al., 2005), was Tamura and Nei (1993) model with gamma-distributed rate variation $(\operatorname{TrN}+\Gamma)$. The analysis was run for 500000 generations with trees sampled every 100 generations. The first 1250 trees were discarded as the burnin of the chain. Default settings of MrBayes were used.

\section{RESULTS}

The phylogenetic relationships of the 17 maples were not fully resolved, as indicated by the polytomies and the low support of some nodes of the consensus tree (Fig. 1). This emphasizes the importance of controlling for phylogenetic uncertainty when testing the evolutionary correlations of shootgrowth polycyclism in Acer.

The observed direction of association between polycyclism and the most important traits defining the first suite of characters in maples indicated that polycyclism was associated with characters that maximize light capture (Fig. 2). Thus, polycyclism was positively correlated with the twig thickness (TCSA), shoot leaf area (ShLA), and leaf size (LfPt) and negatively correlated with the number of growing tips per unit crown area and height (CATP-P, HTTP-P), total shoot length vs. height (HTTL-P), and main stem length vs. height (HTSLP). Correlations with some traits (ShLA, TCSA, and HTSL) were strongly significant and robust to phylogenetic uncertainty because more than $98 \%$ of the $3000 P$ values obtained were statistically significant at the 0.05 level (Fig. 3). Correlations with other traits (CATP-P, HTTP-P, and LfPT) were more sensitive to phylogenetic uncertainty because some $P$ values were slightly greater than 0.05 (Fig. 3 ). The only nonsignificant correlation was that of polycyclism with HTTL, where most of the $P$ values exceeded 0.05 (Fig. 3).

The traits involved in the second suite of characters (i.e., those indicating covariation in crown area [HTCA-S], crown volume [HTCV-P], and total leaf area in saplings of equivalent height [HTTA-P]) were not associated with polycyclism because none of these correlations were statistically significant (Fig. 2). The lack of statistical correlations was clear because all $3000 P$ values exceeded 0.05 (Fig. 4).

Polycyclic maples were taller at maturity than monocyclic maples $(3.0 \pm 0.2 \mathrm{~m}$ vs. $2.4 \pm 0.1 \mathrm{~m}$, respectively; mean estimate and range of the GEE analysis was $0.63[0.45,0.75])$. This relationship was strongly significant and robust to phylogenetic uncertainty because more than $98 \%$ of the $P$ values were less than 0.05 . 

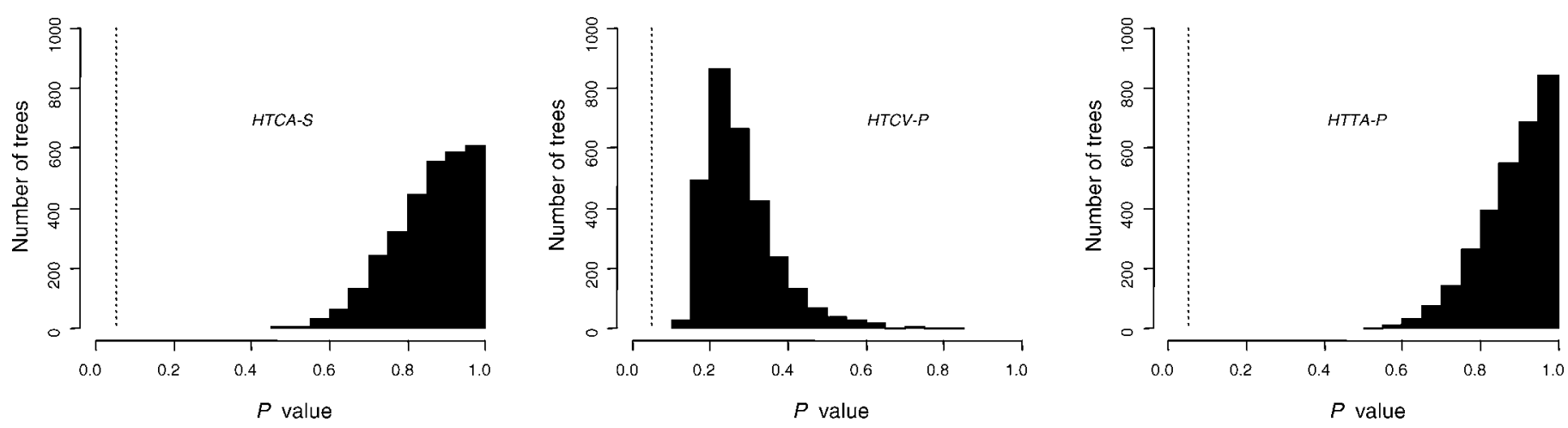

Fig. 4. The frequency distribution of the $P$ values obtained in the 3000 phylogenetic trees that were used to test the evolutionary correlation between polycyclism and the traits involved in the second suite of characters (those allowing shade tolerance) defined by Ackerly and Donoghue (1998). Dotted line indicates $P=0.05$. See Fig. 2 for trait abbreviations.

\section{DISCUSSION}

Polycyclism refers to the programmed change in the developmental sequence of the shoot within a growing season and may affect the functional physiology of photosynthesis, including light interception and self-shading (Diggle, 1999), and ultimately the regeneration patterns of tree species (Seino, 1998). Here, we show that maples with polycyclic growth have characteristics that are associated with a strategy for light capture and not for shade tolerance. Taller growth in the understory is advantageous because it allows trees to capture light; polycyclic trees can grow taller at low cost, with episodic flushes of growth when environmental conditions are good. Following Kohyama (1987), we could categorize the polycyclic maples as "optimists" (i.e., vigorously extending vertically in rich light) and the monocyclic maples as "pessimists" (i.e., trees waiting in the dark understory until a gap opens).

These two strategies are widespread among different floras. For example, many North American shade-tolerant tree species complete most of their shoot growth in the first month of the growing season, while the shade-intolerant trees extend their growth throughout the growing season by means of episodic flushes of growth (Canham et al., 1999). Polycyclism allows the saplings to benefit from the episodic improvement in light, thus widening the regeneration window. For example, Seino (1998) has shown that intermittent shoot growth allows the polycyclic species Acanthopanax sciadophylloides to recruit over a wider range of environments than the monocyclic species (Magnolia obovata and Kalopanax pictus).

Coadapted suites of traits, as those involved in the plant canopy structure in understory maples, may be easily and rapidly produced by heterochronic variation (McKinney, 1999). For example, we have shown that the polycyclic species have faster growth rates and are taller at maturity, what may indicate a heterochronic process like peramorphosis (i.e., a monocyclic ancestor evolving into a polycyclic descendant in which the development has been extended by faster growth or by later cessation of growth) or paedomorphosis (i.e., a polycyclic ancestor evolving into a monocyclic descendant with truncated development by slower growth or by early cessation of growth). Both peramorphosis and paedomorphosis can drive the evolutionary changes in leaf morphology ( $\mathrm{Li}$ and Johnston, 2000). Another kind of heterochrony has been invoked in Acer because polycyclic shoots in adult maples usually have juvenile leaves, suggesting recapitulation of ancestral states (Critchfield, 1971). Alternatively, the presence of juvenile leaves in the adult polycyclic shoots may have nothing to do with heterochrony but may be due to the lower cost of juvenile than adult foliage (Miller et al., 1995; Climent et al., 2006). Moreover, the different level of preformation of metamers in monocyclic shoots (fully preformed) and polycyclic, lammas shoots (less preformed) has profound ecological consequences, linked to the different coupling between the environment at the moment of metamer formation and expansion (Diggle, 1997). Understanding the ecophysiological implications of polycyclism and correlated traits in understory maples will help in developing sounder management practices, aimed at favoring or controlling a given species in the forest system. In addition, this knowledge will help clarify the effects of climate alterations on the phenology of each species and on forest vulnerability to biotic and abiotic agents.

Further research is clearly needed to unravel the plethora of processes acting together with heterochrony on the evolution of polycyclism. Finally, we want to stress that this research would benefit enormously from the development of a comparative method that would allow researchers to track evolutionary changes in developmental, morphological, and ecological traits of the study lineages.

\section{LITERATURE CITED}

ACKerly, D. D., AND M. J. Donoghue. 1998. Leaf size, sapling allometry, and Corner's rules: phylogeny and correlated evolution in maples (Acer). American Naturalist 152: 767-791.

Canham, C. D., R. K. Kobe, R. E. F. Latty, and R. L. Chazdon. 1999. Interspecific and intraspecific variation in tree seedling survival: effects of allocation to roots vs. carbohydrate reserves. Oecologia 121: $1-11$.

Climent, J., R. Chambel, R. López, S. Mutke, R. Alía, and L. Gil. 2006. Population divergence for heteroblasty in the Canary Island pine (Pinus canariensis, Pinaceae). American Journal of Botany 93: 840848.

Corner, E. J. H. 1949. The Durian theory or the origin of the modern tree. Annals of Botany 13: 367-414.

CRITCHFIELD, W. B. 1971. Shoot growth and heterophylly in Acer. Journal of the Arnold Arboretum 52: 240-266.

De Jong, P. C. 1976. Flowering and sex expression in Acer L. A biosystematic study. Mededelingen Landbouwhogeschool Wageningen 76: 1-201. 
Diggle, P. K. 1997. Extreme preformation in alpine Polygonum viviparum: an architectural and developmental analysis. American Journal of Botany 84: 154-169.

DigGle, P. K. 1999. Heteroblasty and the evolution of flowering phenologies. International Journal of Plant Sciences 160: S123S134.

HuelsenBeck, J. P., AND F. Roneuist. 2001. MrBayes: Bayesian inference of phylogeny. Bioinformatics 17: 754-755.

Kaya, Z., W. T. AdAms, AND R. K. CAmpbell. 1994. Adaptive significance of intermittent shoot growth in Douglas-fir seedlings. Tree Physiology 14: 1277-1289.

Kонуама, T. 1987. Significance of architecture and allometry in saplings. Functional Ecology 1: 399-404.

Kosakovsky Pond, S. L., S. D. Frost, and S. V. Muse. 2005. HyPhy: hypothesis testing using phylogenies. Bioinformatics 21: 676-679.

LeI, T. T., AND M. J. LeChOwicz. 1990. Shade adaptation and shade tolerance in saplings of three Acer species from eastern North America. Oecologia 84: 224-228.

Lei, T. T., AND M. J. Lechowicz. 1997a. Functional responses of Acer species to two simulated forest gap environments: leaf-level properties and photosynthesis. Photosynthetica 33: 277-289.

LeI, T. T., AND M. J. LeCHOwICZ. 1997b. The photosynthetic response of eight species of Acer to simulated light regimes from the centre and edge of gaps. Functional Ecology 11: 16-23.

LeI, T.T., AND M. J. LeCHOwICZ. 1998. Diverse responses of maple saplings to forest light regimes. Annals of Botany 82: 9-19.

Li, P., AND M. O. Johnston. 2000. Heterochrony in plant evolutionary studies through the twentieth century. Botanical Review 66: 57-88.
McKinney, M. L. 1999. Heterochrony: beyond words. Paleobiology 25 : 149-153.

Miller, P. M., L. E. Eddleman, and J. M. Miller. 1995. Juniperus occidentalis juvenile foliage: advantages and disadvantages for a stress-tolerant, invasive conifer. Canadian Journal of Forest Research 25: 470-479.

Paradis, E., and J. Claude. 2002. Analysis of comparative data using generalized estimating equations. Journal of Theoretical Biology 218: $175-185$.

Posada, D., and K. A. Crandall. 1998. Modeltest: testing the model of DNA substitution. Bioinformatics 14: 817-818.

SEINo, T. 1998. Intermittent shoot growth of Acanthopanax sciadophylloides (Araliaceae). Annals of Botany 81: 535-543.

SiPE, T. W., AND F. A. BAZZAZ. 1994. Gap partitioning among maples (Acer) in central New England: shoot architecture and photosynthesis. Ecology 75: 2318-2332.

SiPE, T. W., AND F. A. BAZZAZ. 1995 Gap partitioning among maples (Acer) in central New England: survival and growth. Ecology 76: $1587-1602$.

Steingraeber, D. A. 1982. Heterophylly and neoformation of leaves in sugar maple (Acer saccharum). American Journal of Botany 69: $1277-1282$.

TAmuRA, K., AND M. NeI. 1993. Estimation of the number of nucleotide substitutions in the control region of mitochondrial DNA in humans and chimpanzees. Molecular Biology and Evolution 10: 512-526.

Verdú, M., AND G. Gleiser. 2006. Adaptive evolution of reproductive and vegetative traits driven by breeding systems. New Phytologist 169: 409-417. 